Vanina Papalini e Ana Valeria Rizo

\title{
LITERATURA DE CIRCULACIÓN MASIVA, DE LA PRODUCCIÓN A LA RECEPCIÓN. EL CASO DE LOS LECTORES DE AUTOAYUDA
}

\author{
(Mass circulation literature, from production to reception. \\ The case of self-help books readers)
}

Vanina Papalini ${ }^{1}$

Ana Valeria Rizo ${ }^{2}$

(Universidad Nacional de Córdoba)

\begin{abstract}
In this article we will analyze the "mass literature", starting with a conception of literature that distances itself from those that make it correspond to a cultural norm, and which theoretical foundations are inspired both in Cultural Studies and the Aesthetics of Reception. For this, we will analyze a typical case of this "dominant" literature: self-help books. First, we carry out an analysis of the production of these books; later, we focus on their circulation and the composition of their readership, differentiating typical means of reception that let us construct some specific interpretive communities of the self-help genre.
\end{abstract}

Keywords: mass literature, self-help literature, reception, interpretive communities

1. Es Doctora en Ciencias de la Información por la Universidad de París VIII y Doctora en Ciencias Sociales por la Universidad de Buenos Aires. Es investigadora del Consejo Nacional de Investigaciones Científicas y Técnicas (CONICET) de Argentina y profesora de la Escuela de Letras de Universidad Nacional de Córdoba. Dirige el programa de investigación "Transformaciones de la cultura masiva”.

2. Es Licenciada en Comunicación Social y Doctoranda en Ciencias Antropológicas por la Universidad Nacional de Córdoba. Es becaria del proyecto de investigación "Lectores y lecturas: la recepción de la literatura masiva contemporánea", con financiación del Fondo para la Investigación Científica y Tecnológica (FONCyT) de Argentina. 


\section{RESUMO}

Neste artigo, abordamos a análise da "literatura da circulação massiva", partindo de uma concepção que se distancia daquelas que a relacionam ao cânone cultural, e cujos fundamentos teóricos se inspiram tanto nos Estudos Culturais como na Estética da Recepção. Para isso, analisamos um caso característico desta literatura "dominante": os livros de autoajuda. Depois de um primeiro momento, em que realizamos uma análise da produção dos livros, enfocamos a sua circulação e a configuração dos públicos, diferenciando os modos de recepção típicos que nos permitem construir algumas comunidades interpretativas do gênero autoajuda.

Palavras-chave: literatura de circulação massiva, literatura de autoajuda, recepção, comunidades interpretativas

\section{Introducción: literaturas}

¿Qué es la literatura?, se pregunta la teoría. ¿Qué libros pueden ser considerados "literatura"?, se interroga la crítica literaria. ¿Qué libros puedo legítimamente declarar, cuando me interrogan sobre mis lecturas?, se cuestiona el lector.

Las definiciones de literatura son diversas y podrían ordenarse desde las más restrictivas - que la hacen coincidir con aquellos libros que figuran en el canon - con las más abiertas, para las que todo texto es literatura (Bloom, 1995). Existe un amplio abanico de nociones; hay definiciones espiritualistas para las cuales la literatura se vincula con una intencionalidad y factura estética (Jakobson, 1983; Kirchof, 2009); las hay empiristas, para las que "literatura" refiere al conjunto de los libros editados en una nación o una época, o sobre un tema determinado. ${ }^{3}$ Existen posiciones que sostienen que la literatura no está atada a la materia escrita, que reconocen tanto

3. Esta definición es deudora de los usos anglosajones para los cuales la literatura tenía más que ver con quién la producía que con qué se producía: se refería a los escritos confeccionados por las clases instruidas. De ese uso más amplio surgen aplicaciones tales como, por ejemplo, "literatura médica" - para hablar de textos referidos a medicina. 
literaturas "orales" (Colombres, 1998), ${ }^{4}$ como literaturas digitales (Chartier, 1999). Están quienes opinan que la literatura tiene que ver con la experiencia que se produce al leer (Derrida, 1992a; 1992b) y quienes, por el contrario, nunca dejarían tal definición en sede plebeya o de gustos fluctuantes: la "calidad" literaria es materia juzgada por expertos.

Ciertamente, éstos no son más que esquemas simplificados; en las reflexiones pluriparadigmáticas de las ciencias humanas, no hay unanimidad, homogeneidad ni simplicidad, no puede haberla y ni siquiera es deseable que la haya. Asumiendo, entonces, que la determinación teórica sobre la literatura sea una cuestión sin zanjar, optamos por observar los procesos por los cuales emerge como el resultado de un funcionamiento literario, generado por dispositivos sociales complejos. La literatura es entendida en esta investigación como el efecto de un conjunto de reglas objetivas, de inscripción y de lectura, en un espacio cultural específico.

Partimos del supuesto de que la 'cualidad literaria' no es una esencia: desde nuestro enfoque, cualquier texto puede ser leído como literatura y, a la inversa, una obra literaria puede ser leída sin que encontrar en sus páginas nada que abone una experiencia estética o sublime. Concebimos la literatura como el producto de un conjunto de prácticas sociales entretejidas con sus contextos sociales e históricos, no como obra de espíritus elevados despojados de necesidades concretas (Chartier, 1999). Tratamos acciones, procedimientos técnicos y bienes que conjugan un valor simbólico y un valor económico (Thompson, 1998). La mercancía literaria se intercambia en un mercado organizado como tal, es decir que se ajusta a requerimientos de demanda y oferta, a las regulaciones de las transacciones comerciales y a las estrategias de promoción de las ventas (Rama, 2003).

Las definiciones de literatura que la reducen a una de las bellas artes, en la que la lectura se concibe como una práctica cultural

4. Según Adolfo Colombres (1998), la expresión fue creada por Paul Sébillot en 1881. Walter Ong critica esa noción en Oralidad y escritura, argumentando que el término "literatura" significa "escrito" y que es abusivo extenderlo a las narraciones orales (1993: 19-24). 
(Benjamin, 1973), dificulta la comprensión de lo que llamaremos "literatura de circulación masiva". Ésta constituye, justamente, el centro de nuestra atención. Nos interesamos, no en la "gran" literatura sino en las literaturas "dominantes" (mainstream): su valor como obra no será puesto en cuestión puesto que lo que nos interesa es su circulación, recepción y apropiación. El término "dominante" no es una mera traducción sino que abreva en la clásica estratificación de las formaciones culturales proporcionada por Raymond Williams (1980).

El acento puesto en el modo de creación, reproducción y circulación revela a la literatura también como una mercancía en un juego esencialmente capitalista. El estudio del momento de la producción es, entonces, la primera entrada a este problema. La investigación se basa en observaciones en los puntos por los que los libros circulan: librerías y ferias, especialmente; entrevistas a editores y libreros; notas y entrevistas de revistas especializadas e informes de las cámaras y organizaciones en donde ellos se agrupan.

Un segundo momento tiene que ver con la circulación de los libros y la configuración de "públicos": comunidades interpretativas que comparten lecturas y modos de apropiación. Para introducirnos más en profundidad en el universo de los lectores, hemos reducido el campo empírico, escogiendo un caso que permite presentar los distintos ejes de nuestro análisis: se trata de los lectores de libros de autoayuda. A partir de una exploración inicial amplia, diferenciamos modos de recepción "típicos" que permiten distinguir algunas comunidades interpretativas. Esta etapa, que denominamos "etnográfica", se nutre de la información proveniente de un abultado número de entrevistas - más de 90 - y del análisis de foros virtuales de aficionados.

Las herramientas conceptuales de las que nos valemos acompañan todo el proceso de análisis. Por ello, no arribamos a una conclusión final; las categorías emergentes que jalonan este artículo constituyen síntesis teóricas que surgen de un proceso de interpretación permanente. 


\section{La industria del libro}

El funcionamiento del libro en un mercado editorial exige comprender las aristas comerciales de la producción literaria, un aspecto que resulta crucial para hacer inteligibles los procesos culturales contemporáneos. En primer lugar, recordemos que, en los mercados capitalistas, Time is Money: hay plazos de entrega que tienen que ver con los tiempos de rotación en la plaza de ventas. La rueda de la producción, difusión y circulación y comercialización, que se mueve por el interés de obtener una ganancia, requiere un ajuste constante a las nuevas tendencias del mercado (Gil \& Jiménez, 2008).

El circuito de la lectura es impulsado por todos los actores participantes, desde los autores - que trabajan por inspiración, deseo, solicitud, obligaciones contractuales o necesidad -, a la industria editorial, pasando por las comunidades de aficionados, las revistas culturales, las instituciones vinculadas al libro y las maquinarias de otorgamiento de premios, para llegar hasta el público (Ramírez, 2009). Los libros que más se venden pueden ser considerados como títulos unitarios (el best seller), por género (los libros de autoayuda, como un género de grandes ventas) o como serie de un autor o una autoramarca que garantiza el éxito comercial (Stephen King, por ejemplo). Como en toda industria cultural, el amoldamiento a pautas fijas facilita la reproducción en serie (Adorno y Horkheimer, 2006). El género y la saga - como serie narrativa que despliega una historia por etapas - las proporcionan.

Las producciones culturales de circulación masiva presentan un conjunto de características propias (Adorno y Horkheimer, 2006):

(a) Constituyen una "multiplicidad integrada". El oxímoron señala los cambios de la modalidad productiva en la industria cultural, cuya tradicional producción en serie ha derivado en la customization, es decir, la diversificación de la producción atendiendo a los requerimientos de distintos segmentos de mercado. El aprovechamiento del núcleo 
creativo - el argumento, los personajes - de cualquier producto cultural es variado e intensivo. En lugar de circunscribirse a un solo producto, se utiliza en numerosas aplicaciones y soportes materiales. Sobre un mismo núcleo creativo, generalmente argumental o narrativo, se fabrican agendas, videos, películas, libros, merchandising, páginas web, e-books. Siguiendo la misma lógica, se diversifican igualmente los nichos a los que se dirige el producto: adolescentes, familias, ejecutivos, para el tiempo libre, para leer camino al trabajo, etc.

(b) El autor funciona como marca. Los autores de éxito y reconocidos por los públicos pueden convertirse en marcas comerciales, en firmas identificables, tanto más valoradas cuanto mayor sea su éxito en términos de ventas. La circulación de un texto en el mercado editorial exige una identificación del binomio libro-autor como rúbrica comercial. Esta "función de autor" (Foucault, 2010), donde el nombre propio, vacío como identidad de un sujeto concreto, es tanto un constructor social como lo es la obra misma, condensa el trabajo conjunto de autores, editoriales, sistema de publicidad y crítica experta. El nombre propio adquiere un valor mercantil a partir de las estrategias publicitarias, los sitios web, las revistas especializadas, los suplementos de cultura y el sistema de medios en su conjunto, incluyendo segmentos radiales y televisivos, columnas, entrevistas y diversos espacios en los que el autor o la autora se muestran. La mercadotecnia se basa en estas signaturas reconocibles que destacan un producto frente a otros que compiten con él.

(c) Existe una alta rotación y encadenamiento de productos. Dado el corto ciclo de circulación de los libros orientados a la venta masiva, se requiere lanzar nuevos productos al 
Vanina Papalini e Ana Valeria Rizo

mercado continuamente. Los cánones del género y los estilos y estructuras narrativas que caracterizan a cada autor o autora favorecen una alta rotación del libro, permiten la multiplicación de títulos nuevos bajo un esquema de resultados conocidos y facilitan su circulación en el mercado global. El despliegue de un título exitoso como serie multiplica las posibilidades de ventas y reduce el riesgo de la innovación. Existe una demanda de "novedad", pero esta novedad es apenas un matiz de diferencia sobre una receta de resultados comprobados

El siguiente ejemplo ilustra claramente las tres características de la industria editorial que hemos presentado antes: se trata de la serie de libros y otras piezas derivadas de Los siete hábitos de la gente altamente efectiva de Stephen Covey. Perteneciente al género de la autoayuda, ostenta palmariamente las características de la serialidad, las necesidades de la rotación y el funcionamiento orientado al mercado. Estos rasgos, que no son privativos de este género, se revelan en el ejemplo sin pudor alguno.

The 7 Habits of Highly Effective People, 1989 [1992]; Daily Reflections for Highly Effective People: Living the 7 Habits of Highly Effective People Every Day, 1994 [1997]; Renewal: Nourishing Body, Mind, Heart, and Soul (The Portable 7 Habits Series), 1999; The 7 Habits of Highly Effective People (edición miniatura), 2000; Living the 7 Habits: The Courage to Change, 2000; The Power of the 7 Habits (Audio CD), 2000; The 7 Habits Journal, 2002; Beyond the 7 Habits (Audio CD) 2003; The 7 Habits of Highly Effective People Personal Workbook, 2003; The 7 Habits of Highly Effective People (Audio CD), 2005 [2007]; The 7 Habits Signature Series Set (Audio CD), 2006; The 7 Habits of Highly Effective People 2009 Calendar, 2008. Existen también CDs, uno por cada hábito: Habit 1, Habit 2, Habit 4, Habit 5, Habit 6, Habit 7, 2006.

The 8th Habit, 1990 [1995]; The 8th Habit Personal Workbook, 2006, The 8th Habit, (Audio CD) [2007]. 
The 7 Habits of Highly Effective Families (con Sandra Covey), 1997 [1998]; The 7 Habits of Highly Effective Marriage (con Sandra Covey), 2008; The 7 Habits for Managers, 2009. The 7 Habits of Happy Kids (Sean Covey and Stacy Curtis), 2008.

The 7 Habits of Highly Effective Teens (Sean Covey), 1999 [2005]; Daily Reflections For Highly Effective Teens (Sean Covey), 1999; The 7 Habits Journal for Teens (Sean Covey) 2002; The 7 Habits of Highly Effective Teens (Miniature Edition) (Sean Covey) 2003; The 7 Habits of Highly Effective Teens Personal Workbook (Sean Covey) 2003; The Choice is Yours: The 7 Habits Activity Guide for Teens (Sean Covey y Franklin Covey) 2007.

El primer fragmento muestra la diversificación de soportes: libros, opúsculos, CDs, folletos, videos, ediciones miniatura, agendas, a los que se agregan los contenidos web y las clínicas y talleres. También ejemplifica la serie narrativa: los siete hábitos para distintos grupos como familias, matrimonios, "managers", adolescentes. Vemos también que el autor-marca extiende el sello para incluir a otros "Covey" - familiares de Stephen: Sean, Sandra y Franklin que participan de la empresa. Tomada como totalidad y viendo la periodicidad de la aparición de "novedades" a partir del mismo núcleo creativo, se ejemplifica claramente la alta rotación: de 1989 a 2007, y según lo que pudimos registrar, pueden contabilizarse 27 productos y numerosas reediciones de cada uno, es decir, más de uno por año.

No obstante, recordemos que la industria editorial opera en el espacio simbólico: los hábitos de los lectores y las pautas idiosincráticas tienen una gravitación importante, tanto, que es difícil pensar en la simple "penetración" e inundación del mercado de producciones importadas. Esta constatación nos lleva a plantear, por último:

(d) Articula procesos de internacionalización con la localización de los mercados editoriales. Si bien existe una amplia traducción, el mercado editorial incluye autores nacionales que adaptan los géneros preferidos por los 
Vanina Papalini e Ana Valeria Rizo

públicos a las pautas culturales locales. Además, la relación con los autores está fuertemente tramada con el sistema de medios; por ello, la posibilidad de reconocimiento es mayor. La cercanía es un dato relevante, como prueba la concurrencia de las presentaciones de libros en donde, aún sin haber leído el texto, los lectores concurren para acercarse a los autores. La adaptación y recreación de géneros, temas y pautas transnacionales con autores locales es más frecuente en países con una industria editorial fuerte, como lo son México, Colombia, Argentina y Brasil en América Latina (SIER/CERLALC, 2008).

\section{Literatura de circulación masiva}

Definida en el universo anglosajón como mass literature, se trata de la producción destinada al "gran público". Su delimitación sólo puede entenderse dentro del universo de las industrias culturales. La literatura masiva remite a la manera en la que los libros se producen (en serie, es decir, se trata de una fabricación industrial) y las ideas sobre el público que presiden las decisiones de edición. De entrada nos encontramos, entonces, con una prefiguración del destinatario o consumidor; un lector o una lectora que compra libros, o una institución que los compra por ellos. Esta suerte de lector hipotético, desindividuado y abstracto, es concebido a partir de información parcial, de "variables", que permiten "caracterizar" el conjunto. La información estadística o cuantitativa trata lectores y lectoras singulares como componentes de una totalidad de la cual se ponen en foco unos pocos rasgos: los libros de circulación masiva no están destinados a priori a "individuos" con una particular y específica sensibilidad, sino a un público amplio en términos cuantitativos, pensado como subgrupos o segmentos en función ciertos datos que les otorgan homogeneidad (jóvenes, interesados en política, mujeres, aficionados al género del terror, etc.

La definición que utilizamos - literatura de circulación masiva - es una traducción matizada del término mass literature, que tiende 
a enfatizar la lógica de amplio alcance que rige la producción, la promoción y la distribución de estos bienes, considerando sus dinámicas y circuitos. Incluye tanto las novelas y ensayos como los textos llamados "paraliterarios" (Boyer, 2008): novelas rosa, historietas y folletines, libros de autoayuda, investigaciones periodísticas, libros de divulgación histórica, etc. Reducimos también, así, las connotaciones negativas del término "masa" (Swingewood, 2003) que evoca la idea de un conglomerado homogéneo de destinatarios y, en este sentido, oscurece más de lo que revela. En realidad, las muy efectivas estrategias de las industrias culturales operan a partir de nítidos perfiles de sus públicos-meta.

La literatura de circulación masiva se distingue de la literatura underground o "de culto". ${ }^{5}$ En ambos casos, la definición enfatiza las características de su circulación: en un caso es amplia; en el otro, restringida. Al ponderar este aspecto, no estrictamente cerrado sobre sus condiciones de producción, como ocurre con el término anglosajón, se hace visible la cuestión de los contextos: un libro que en un determinado medio es de circulación restringida, en otro puede ser de consumo masivo.

El momento de la circulación (Hall, 1980) es un aspecto no suficientemente enfatizado en los análisis culturales: su valor heurístico residen en que permite investigar la trama y enfocar con mayor interés las interacciones y los procesos de intercambio, destacando los atributos sociales, culturales y contextuales en la trayectoria, la diversidad de las apropiaciones (Zires, 2005) y los a veces curiosos "destinos" de los bienes simbólicos. Así, la determinación de un tipo de literatura a partir de sus modos de circulación pretende subrayar: a) las dinámicas, procesos y trayectorias del objeto libro; b) los contextos culturales e histórico-sociales de su apropiación y desplazamiento, en un movimiento que consideramos de "comunicación" - esto es, se trata del movimiento de intercambio de y en torno al libro, que transita

5. No es la literatura underground objeto de esta investigación, de manera que la distinción es sólo teórica. Valdría la pena emprender una investigación que permita saber qué tanto se distancia de los procedimientos que describimos para la literatura de circulación masiva. 
Vanina Papalini e Ana Valeria Rizo

distintos circuitos y c) el carácter social, colectivo, de las prácticas culturales que incluyen al libro, inclusive la de lectura, aunque haya sido tradicionalmente pensada como una actividad solitaria e individual.

\section{Circuitos de lectura y comunidades interpretativas}

Walter Ong ha descrito la lectura del libro impreso como una actividad individual y recluida, concordante con los modos de relación y de producción de conocimiento de la modernidad. Asignando al libro impreso un lugar destacado en el proceso de transformación cultural, opone el modo de apropiación individual que supone la lectura silenciosa del libro a los modos colectivos que propiciaba la lectura en voz alta (Ong, 1993). Tradicionalmente, y en coincidencia con la perspectiva de Ong, se ha asumido la lectura como una práctica solitaria y personal, que abona la interpretación propia (Rosenblatt, 2002). Sin embargo, aún cuando el acto de lectura sea una práctica privada, está inscrita en un circuito de intercambio y comunicación social. Sus anclajes nunca se produce desde el aislamiento: pensamos, creemos e interpretamos en una interacción continua con los otros, en el horizonte de un universo simbólico y a través de palabras - que son ajenas y hacemos propias (Bajtin, 1999) -, en las que se depositan los sedimentos de las largas travesías socioculturales.

Preguntémonos cómo se decide adquirir un libro. Existen recomendaciones, alguien lo presta o lo regala, alguien habla de él y suscita interés, o forma parte de un programa de estudios y es mencionado por un docente. También hay modos impersonales: se exhibe en un estante de una librería con una tapa llamativa o con fajas donde se anuncian sus reiteradas ediciones y su éxito en otros países, se ofrece en un catálogo accesible desde Internet, se recibe una gacetilla anunciando su aparición o una invitación a su presentación, se comenta su publicación en un programa radial. El libro da lugar a notas y comentarios de revistas especializadas, integra el ranking de los más vendidos, su autor es galardonado, la obra recibe un 
premio. Hemos identificado así tres modos de llegada, tres órdenes de recomendación: interpersonal, comercial y experta.

La definición de literatura de circulación masiva, por lo tanto, remite a la manera en que un objeto específico - el libro - recorre las nervaduras de la sociedad. Si "no hay tal cosa como un lector genérico o una obra literaria genérica"; tampoco hay "millones de lectores individuales potenciales de millones de obras literarias potenciales", como parece creer Louise Ronsenblatt (2002: 51). Los lectores no son individuos separados entre sí: forman parte de una o varias tramas en relación con las cuales construyen sus múltiples identidades lectoras. Existen circuitos de especialistas, voces autorizadas, recomendaciones de personas en quienes se confía o a quienes se les reconoce un saber. Existen además grupos de aficionados a cierto tipo de literatura, comunidades virtuales, cofradías o grupos que frecuentan cierta librería o cierta biblioteca. También están los eventos públicos, las ferias, las entrevistas: el sistema de la industria cultural se retroalimenta y multiplica todo el tiempo, se renueva, cambia de soporte: del libro a la película, de la revista al libro, de la película a la serie televisiva.

La comprensión del universo de los lectores en sus agregaciones requiere abrevar en la noción de "públicos". Gabriel Tarde (1986) acuña este término para designar la actividad de la recepción en una sociedad mediatizada (Tarde, 1986: 45-47), sociedades democráticas y plurales en el sentido ideológico: sociedades "modernas" ligadas al surgimiento de la prensa. Tarde plantea la posibilidad de clasificación de los públicos a partir del sexo, la edad y la clase social con el tipo de consumo (Tarde, 1986: 61, ${ }^{6}$ como lo hará cien años más tarde Bourdieu al proponer el concepto de habitus (BOURDIEU, 1997).

La convergencia entre la noción de públicos, la estética de la recepción y la teoría de la recepción de Escuela de Birmingham nos permite pensar de manera particularmente fructífera la situación de los lectores y lectoras de la literatura de circulación masiva. Por un

6. "Cada uno de nosotros, al comprar lo que responde a nuestras necesidades, tiene más o menos vagamente conciencia de expresar y de desarrollar por ello su unión con la clase social que se alimenta, se viste, se satisface en todo, de una manera casi análoga” (Tarde, 1986: 54). 
Vanina Papalini e Ana Valeria Rizo

lado, la estética de la recepción conceptualiza la actividad de la lectura, señalando que el texto se abre como un espacio de indeterminación (Iser, 1987): la imaginación y la interpretación singular dan lugar a representaciones mentales diversas. La lectura se muestra como una actividad que pone en juego competencias culturales y cognitivas para dar lugar a algo "nuevo", que completa el texto. El sentido no está determinado por la obra sino que surge de un intenso diálogo entre la obra y su lector.

Pero este lector no se ubica en el vacío. Las nociones de Hans Jauss de "horizontes de expectativas" y de "horizontes de experiencia", conjugan al sujeto y su horizonte epocal: el público reinterpreta la obra en función de su "actualidad". Los "pactos de lectura" -fruto de la experiencia intersubjetiva- lo condicionan y le permiten hacer anticipaciones. La actividad interpretativa de la lectura se revela como una dialéctica (JAUSS, 1987; 1992).

Entendemos los horizontes de experiencias como un patrimonio público, no individual. Las experiencias se simbolizan a partir de significaciones sociales circulantes y accesibles (Geertz, 1997). La lectura puede constituir un "espacio propio" y permitir una vía de comprensión subjetiva y de trabajo personal autónomo (Petit, 2006), pero lo hace en relación con las estructuras y objetivaciones existentes y bien conocidas. Los lectores y las lectoras llegan al texto con un sistema de referencias previo, lo cual limita la deriva absoluta de las apropiaciones. En este sentido, Stanley Fish propone la noción de "comunidades interpretativas" señalando límites al completo subjetivismo de la aproximación de los lectores y lectoras: en tanto forman parte de una comunidad lingüística, la lengua propia, compartida con el resto de los hablantes, establece límites normativos a la experiencia individual del lenguaje (FISH, 1976; VARELA, 1999).

Queremos señalar un aspecto menos general que, entendemos, es lo que hace productivo el concepto de "comunidades interpretativas", dándole un mayor valor heurístico que el de "comunidades lingüísticas": la noción deja entrever que los miembros de estas comunidades comparten un mismo "anclaje de sentido" (Barthes, 1995): participan de una constelación de significaciones comunes, articuladas de 
manera semejante, estableciendo configuraciones similares a partir de las significaciones presentes en una obra. Generalmente esta estructuración compartida está vinculada al horizonte de experiencia, más que al horizonte de expectativas, no sólo por lo que las trayectorias y vivencias puedan tener en común, sino porque la construcción se realiza como experiencia, en la interacción entre los miembros de esta comunidad.

Esto equivale a decir que no se trata necesariamente de grupos homogéneos según los criterios sociológicos: las edades, las profesiones, los recursos económicos, pueden ser desiguales. La conformación de comunidades interpretativas se comprende en el terreno: aún cuando puedan ser prefiguradas socialmente en las estrategias que proponen las industrias culturales, su consumación está en tensión con los presupuestos de la producción. El "resultado" es diverso, plural y parcialmente indeterminado.

\section{La literatura de autoayuda y sus lectores}

Las comunidades interpretativas son congregadas por afinidades múltiples. La exploración de campo revela que una de las preferencias que las aglutina está determinada por la fruición de determinados géneros. El género es un gran organizador que orienta la elección en relación con las experiencias "buscadas". Es una convención intersubjetiva que implica, básicamente, la adhesión a una legalidad, a "reglas" que se entraman con el horizonte de expectativas de los públicos (Steimberg, 2002). Ciertamente, éstas no son transhistóricas ni fijas: son herramientas de tipificación de cada tiempo.

Mijail Bajtín (1999) señala que la preponderancia de un determinado género en una época histórica marca su tonalidad emotiva y su peculiaridad cultural. Siguiendo esta premisa, y dada la marcada preferencia que observamos por la literatura de autoayuda, proponemos seguir el rumbo de sus lectores.

Enunciaremos algunos de los parámetros que utilizamos para la definición de los libros de autoayuda. Aunque puede encontrarse una 
gran diversidad de temáticas y enfoques que permiten su clasificación en sub-géneros, el tema de la "solución de problemas" es común a todos ellos (Papalini, 2007). Se presentan como una estrategia al alcance de la mano para resolver diferentes problemas cuya clave se ubica en el propio sujeto. Su función suele ser utilitaria: si abordan la interioridad del sujeto, es expurgando del relato aquello que singulariza el relato de la vivencia para facilitar la síntesis. Los libros de autoayuda suelen publicitar su eficacia fuera de los límites del texto. En ellos hay una promesa condicionada para aquel lector que sigue el camino indicado por el texto.

La heterogeneidad que se constata en el campo de la producción de la literatura de autoayuda tiene su equivalente en el ámbito del consumo. Los lectores de libros de autoayuda se caracterizan por su diversidad en cuanto a trayectorias socioculturales, contextos sociales, modos de apropiación y usos. Esta variedad de lectores, lecturas y usos sociales de los libros, sumado a características específicas de las sociedades a las que pertenecen, torna complejo el análisis del mundo de la recepción. Sin perder de vista esta densidad, proponemos una aproximación hacia este universo a través de entrevistas realizadas a lectores que habitan en dos ciudades importantes de Argentina: Córdoba y Buenos Aires. ${ }^{7}$

\subsection{Constelaciones de sentidos}

$\mathrm{Si}$ imaginamos los sentidos producidos en torno a la literatura de autoayuda como una red que ata una variedad de interpretaciones singulares en "nudos semánticos" - esto es, condensaciones de sentido en torno a una significación central que cumple la función de anclaje

7. Desde 2010 realizamos un amplio trabajo etnográfico en estas ciudades, en el marco del proyecto "Lectores y Lecturas: la recepción de la literatura masiva contemporánea", dirigido por Pablo Semán. Buenos Aires es la ciudad capital del país y registra, según el censo 2010, 2.890.000 habitantes aproximadamente. Córdoba es la segunda ciudad en importancia, con alrededor de 1.330 .000 habitantes según el mismo censo. Tiene una cultura local fuerte, muy distintiva. La selección de estas ciudades toma en cuenta el dato cultural local y aspira a captar sus matices -si ellos aparecen como relevantes- componiendo universos de lectores eminentemente urbanos con diferencias culturales contextuales. 
-, podremos ver las continuidades que existen entre una lectura y otra, sin reducir la complejidad del análisis. Así, en los casos que hemos trabajado, se hicieron visibles dos nociones o "nudos" significativos que organizan los sentidos plurales construidos en el ámbito de la recepción de esta literatura.

Por un lado, el éxito aparece como una noción clave que condensa y articula un vasto campo semántico y una perspectiva de mundo. El prestigio, el capital económico acumulado y el modo de relación con las personas son susceptibles de ser exitosos o no y en función de prescripciones precisas, es posible corregir y pasar de un estado al otro. Por otro lado, la significación de sanación - clave de un tipo de bienestar - articula otro conjunto de nociones que pueden abarcar las mismas dimensiones que el éxito, bajo una perspectiva distinta. El cuerpo, la vida en relación o afectiva, el espíritu, pueden ser sanados. Estas dos nociones, se constituyen en objetivos a alcanzar para lograr un crecimiento de sus vidas personales y acercarse a un estado mayor de felicidad. Al erigirse en vectores que guían sus prácticas cotidianas, componen una ética específica.

El éxito y la sanación están vinculados a creencias, prácticas, valores y discursos que forman parte del acervo del sentido común de la sociedad a la que pertenecen estos lectores, conformando una base de significaciones sociales compartidas sobre la cual se asienta la eficacia de los preceptos de la autoayuda. Sus fundamentos pueden ser diversos. Indentificamos creencias de corte religioso promovidas por una espiritualidad laxa propia del movimiento de la New Age (Carozzi, 1998; Papalini, 2008; Rüdiger, 1996); discursos científicos o pseudocientíficos, incluido el uso de teorías de física cuántica y neurociencias; diferentes vertientes teóricas de la psicología (Illouz, 2010; Papalini, 2008) y modelos de gestión de las relaciones laborales y personales derivadas del management y de una ética protestante del trabajo (MUR EFFING, 2009).

Podemos elaborar en primera instancia una tipología - que, dada la amplitud y diversidad del universo de lectores de autoayuda no pretende ser exhaustiva -, de acuerdo a la proximidad de los sentidos constituidos en el ámbito de la recepción en relación con los nudos 
semánticos de la sanación o del éxito. En ambos casos, los polos están estrechamente vinculados con un conjunto de prácticas: los lectores de autoayuda se caracterizan por un uso instrumental de las lecturas en función de la resolución de conflictos y malestares relevantes en sus vidas cotidianas.

Así, en el transcurso de nuestra investigación identificamos tres comunidades interpretativas de lectores. A partir de un horizonte de expectativas común, encontramos apropiaciones interpretativas y usos vinculados con sus trayectorias personales $\mathrm{u}$ horizonte de experiencias: a) Los lectores "autoterapeutas", cuya lectura se enmarca en un proceso de búsqueda espiritual (del "ser interior") que incorpora de manera significativa las prácticas de terapias alternativas vinculadas al movimiento de la New Age. b) Los lectores "religiosos", quiénes interpretan la literatura de autoayuda en base a su pertenencia en comunidades religiosas; por lo que en última instancia los significados y los usos de los libros se realizan de acuerdo a un dogma religioso específico. c) Los lectores "empresarios", cuyo uso de la autoayuda tiene su fundamento en el interés del desarrollo en lo económico y al mundo laboral.

Existe un cuarto tipo de lectores que no puede ser incluido en la categorización anterior ya que no se relaciona tanto con los sentidos, éticas y creencias referidas, como con una teoría que tiene fuerte presencia en el campo de la psicología argentina: el psicoanálisis. Se trata del caso de los lectores de Gabriel Rolón, un psicoanalista argentino que tiene amplio reconocimiento por su participación en los medios de comunicación, y cuyos libros se encuentran en el límite del género de la autoayuda. Por su especificidad, no lo desarrollaremos en el marco de este trabajo.

\subsection{La sanación y los lectores "terapeutas" y "religiosos"}

La idea de la sanación está presente en la mayoría de los discursos de los lectores que hemos entrevistado, adquiriendo diferentes matices en cada uno de ellos. Vinculada causalmente a un malestar o sufrimiento percibido por las personas, hace referencia a la 
recuperación de un estado previo que sería inherente a la naturaleza humana: un estado de salud física y espiritual que se ha perdido por diferentes causas. Estas causas y las concepciones que fundamentan el modo eficaz de su recuperación varían en dos líneas generales de acuerdo a las comunidades interpretativas establecidas.

Por un lado, están los sentidos construidos por los lectores que forman parte de la red del "complejo terapéutico alternativo". ${ }^{8}$ Ellos tienen en común el hecho de ser profesionales, pacientes o alumnos de terapias alternativas como el reiki, los masajes ayurvédicos, el Taichi, la Metafísica, etc. Los libros que leen están relacionados con estas terapias y una espiritualidad que mixtura diferentes religiones orientales con las ideas originadas por la corriente del nuevo pensamiento que postula el poder de la mente (Rüdiger, 1996: 72), y que son retomadas por el movimiento de la New Age: libros de autores como Osho, Krishnamurti, Eckhart Tolle y Brian Weiss, entre otros.

Este es el motivo por el cual los hemos denominado lectores "autoterapeutas", ya que el uso de los libros de autoayuda va en la misma dirección que la realización de todas estas prácticas alternativas: la propia sanación, que para ellos comprende lo espiritual y lo corporal en forma holística. Anhelan la integración de la mente, el cuerpo y el espíritu en su búsqueda del ser interior perdido a causas de las enseñanzas erróneas y las estructuras impuestas por la sociedad a la que pertenecen: "El ser interior es el conectarte con la vida más desde el sentir. (...) La mente es como un radar. Va captando todo lo del entorno y vos vas repitiendo conductas. Entonces la idea de esto es llevarte cada vez más hacia adentro y que vos te descubras." (SABRY, REIKISTA, 40 años).

En general, los libros circulan por estos grupos o son recomendados en alguna instancia interpersonal. El circuito de los

8. Según Carozzi (1998) "el complejo alternativo es hoy una red internacional de individuos que participan de manera intercambiable como consultores y consultantes ; coordinadores y participantes de talleres o work-shops; conferencistas y miembros de auditorios ; maestros y discípulos ; terapeutas y pacientes de una amplia variedad de disciplinas y técnicas nutricionales, terapéuticas, psicoterapéuticas, del movimiento corporal, esotéricas, espirituales y místicas occidentales”. 
Vanina Papalini e Ana Valeria Rizo

lectores autoterapeutas está vinculado con almacenes de productos naturales, herboristerías, librerías específicas, publicaciones periódicas, además de los numerosos espacios de prácticas conjuntas: talleres, clínicas, retiros.

Dado que esta espiritualidad no reclama la adhesión a un dogma religioso o a una institución particular, la sanación se vuelve una meta accesible: aparece vinculada con una "energía" que brota de la divinidad, que mueve y conecta a todos los seres "en vibración perfecta y divina”, como expresa Clarisa (reikista, 30 años).

Por el otro lado, los lectores "religiosos" son otro conjunto de sujetos que también realizan sus lecturas en torno a la idea de la sanación, cuyo sentido adquiere un matiz diferente por su articulación con las creencias provenientes de un dogma religioso. Muchos de estos lectores pertenecen a movimientos cristianos (por ejemplo, el movimiento de cristianismo práctico Unity) o son fieles de una congregación religiosa cristiana. El punto de partida de la creencia religiosa cristiana marca un límite externo a las interpretaciones y uso de los libros de autoayuda: ellos se interpretan a partir de su vinculación con los principios sagrados escritos en la Biblia, que oficia así como "sobredeterminación" o al menos, contexto hermenéutico mayor de las significaciones de los libros. Así, la sanación también es la superación de un malestar, pero que se realiza en una dimensión trascendente gracias a la intervención de Dios. Dice Liz (63 años, Ministro de Unity): "Yo como hijo de Dios no heredo enfermedades".

En Argentina, existe un caso sumamente interesante de fieles de una congregación cristiana que leen los libros de autoayuda escritos por el propio pastor que guía la Iglesia. Se trata de Bernardo Stamateas, pastor del Ministerio Presencia de Dios en Buenos Aires, que ha escrito más de 45 libros - entre los más conocidos: Gente Tóxica, Emociones Tóxicas; Pasiones Tóxicas; Fracasos exitosos; Resultados extraordinarios - consumidos masivamente en todo el país, incluyendo lectores que profesan su mismo credo. Los lectores miembros del Ministerio Presencia de Dios resaltan la capacidad del autor de narrar como si fueran anécdotas de "su" propia vida cotidiana, pasajes del viejo y del nuevo Testamento (BATTAGLIA y RIZO, 2011). 
Las comunidades religiosas desarrollan una relación de compromiso interpersonal mayor, instituyen una dinámica regular de encuentros y son relativamente más estables en su composición. La figura del líder (normalmente, los pastores o ministros) es un aglutinante fuerte. Las búsquedas de información y los circuitos está ligados al culto -radios, semanarios, folletos, reuniones.

\subsection{El éxito y los lectores "empresarios"}

Los lectores "empresarios" son aquellos que leen los libros de autoayuda motivados por la búsqueda de un crecimiento en el ámbito laboral. La mayoría de estos lectores tienen o proyectan un negocio independiente, o son empleados de corporaciones y la promoción de estos libros se efectúa en capacitaciones y seminarios (como es el caso de los distribuidores de la empresa de multinivel Herbalife). En consecuencia, sus lecturas se orientan hacia obras cuyas temáticas centrales son los negocios, el marketing, la empresa y el management. Entre las preferencias de este grupo se destacan Padre rico, padre pobre (R. Kiyosaki), Piense y hágase rico (N. Hill), La ciencia de hacerse rico (W. Wattles), Las 7 leyes espirituales del éxito (D.Chopra) y El Secreto (R. Byrne).

El objetivo primordial que se intenta alcanzar a partir de la lectura de estos libros es la excelencia y, sobre todo, su consecuencia: el éxito, un éxito que puede ser medido con el incremento de la riqueza que implicaría una mejor calidad de vida. Para estos lectores, ser millonarios es un objetivo asequible; la riqueza se vuelve un valor moral acorde a una ética del trabajo desarrollada en diferentes ámbitos laborales objetivada, precisada y reforzada por la lectura de estos libros. Para estos lectores, los libros de autoayuda son excelentes manuales prácticos para alcanzar el éxito laboral: un repertorio de técnicas que el sujeto debe aplicarse a sí mismo y que se basan en la premisa de que el principal motor del cambio para el enriquecimiento material y espiritual lo constituye el "pensamiento positivo". Bajo el supuesto de que la mente se impone a la materia, afirman que "te conviertes en lo que más piensas, pero también atraes lo que más piensas” (Byrne, 2007: 23). 
Vanina Papalini e Ana Valeria Rizo

Una de las características prominentes de este tipo de libros es que retoman "la noción de 'interioridad' desde una perspectiva que la traduce en términos productivos-económicos” (Papalini, 2008: 4). En concordancia con este enfoque, un lector nos ofrece una interesante interpretación al definir a esta literatura como "filosofía de negocios" (Federico, 26 años, distribuidor de Herbalife). La definición articula dos tipos de fundamentos discursivos de la autoayuda. El primero: "filosofía" es "ciencia"; es decir que lo que estos libros enseñan está fundado científicamente. Dice Federico: "la riqueza es una ciencia exacta. Cuando uno empieza a pensar de cierto modo, empieza a trabajar con la ley de la abundancia". El segundo: "filosofía" es "espiritualidad", porque estas lecturas implican un "crecimiento interno" en relación a ciertos valores, en especial los promovidos por el movimiento de la New Age.

La primera línea argumentativa justifica la eficacia de las prácticas enunciadas en los libros a través de un discurso secular típico de la modernidad. La segunda, en cambio, transita básicamente por la formación discursiva en la cual la autoayuda ocupa un lugar central; un lugar desde donde estas significaciones expanden su difusión. Se ubica en el plano de los valores morales que sustentan la práctica. En definitiva, se trata de un conjunto de sentidos interrelacionados: una "filosofía de negocios" implica una relación entre los negocios, la riqueza, la espiritualidad y la ciencia, que conduciría a estos lectores al éxito en sus vidas personales.

\section{Consideraciones finales}

En el conjunto de comunidades interpretativas abordadas, hay una manifiesta homogeneidad interna que surge no sólo de las acciones propiciadas desde las instancias de producción, sino también de este tejido conjunto de significaciones de los públicos. El caso específico de los lectores de autoayuda muestra ciertas prácticas compartidas, específicamente vinculadas a este tipo de consumo literario, que tiene el propósito de continuar la efectividad del texto en la refiguración de la existencia. 
En otros casos encontramos patrones parecidos. Las comunidades interpretativas pueden aglutinarse a través de la participación en otro tipo de prácticas, ya sean virtuales o de copresencia física: la lectura de circulación masiva constituye públicos y propicia actividades de sociabilización y "puesta en común”. Así, las reuniones de "cosplay" (costume play: interpretación de personajes con vestimentas características), las fiestas y los encuentros en ciclos de cine son frecuentes en los lectores de manga (Díaz, 2011). Las lectoras de novela romántica aficionadas a cierta autora pueden organizar encuentros es los que, inclusive, llega a hacerse presente la escritora celebrada (Niño, 2011). Las prácticas varían según la comunidad interpretativa de la que se trate. En todos los casos, la obra un punto de una red de relaciones múltiples de intercambio simbólico donde las significaciones se traman con las actividades compartidas.

Todos los lectores entrevistados intercambian sus lecturas y tejen sus interpretaciones al calor de sus prácticas actuales y pasadas, sus diálogos y sus vivencias. La lectura forma parte de la vida cotidiana y se implica en ella de diferentes maneras:

a) Es parte de la acción social cuando, bajo la forma de un manual o sintetizada como instrucción, una lectura prescribe o informa distintas actividades. Es lo que sucede, por ejemplo, al seguir una receta o un conjunto de "secretos" para un liderazgo eficaz, pero también puede extraerse una fórmula de seducción a partir de una novela que no ha sido escrita a priori con esa intención.

b) Construye representaciones en términos de las cuales se concibe al mundo: las relaciones de pareja a la luz de las novelas románticas, el trabajo como batalla o competencia, la ciudad como una jungla, la mente como un radar, etc.

c) Es el contenido de una comunicación: hablamos de lo que leemos, hacemos su exégesis, compartimos ideas.

d) Es la puerta a un espacio íntimo. Permite la introspección y el trabajo interior, ayuda a objetivar emociones y estados anímicos y a establecer analogías entre las situaciones narradas y las vividas. 
e) Es un contenido que se anuda a experiencias biográficas y sirve como llave de la memoria. En ese sentido, forma parte de las huellas mnémicas: "marca" - como la música, como determinados olores - el recuerdo.

Estas capacidades están presentes en toda literatura; la alta y la baja, la de culto y la masiva. Por esta razón, explorar la recepción literaria es el complemento imprescindible de cualquier estudio sobre las literaturas. Las apropiaciones son diversas y, lejos de ser individuales, están conformadas por la trama social y cultural de la que lectores y libros forman parte.

Dada la necesaria brevedad de este texto, hemos podido exponer sólo algunos pocos elementos de cada momento del proceso. Esperamos sin embargo que hayan podido ser suficientes como para comprender el circuito de la lectura de los libros de circulación masiva. Creemos también que esta investigación aporta elementos para sostener que la lectura no constituye un fenómeno individual, ni completamente definido desde las "gramáticas de producción" - aunque éstas, sin duda, juegan un papel relevante - ; que la deriva absoluta en la producción de sentidos no es posible y que, en cambio, las tramas y circuitos en los que los lectores se insertan van conformando las constelaciones de significaciones compartidas que, como un caleidoscopio, constituyen las configuraciones culturales del presente.

Recebido em: março de 2012

Aprovado em: setembro de 2012 vaninapapalini@gmail.com/valerizo@gmail.com

\section{Bibliografía}

Acosta Gómez, L. El lector y la obra. Madrid: Gredos, 1989.

Adorno, T. y Horkheimer, M. La industria cultural. Ilustración como engaño de masas. In Dialéctica de la Ilustración. Madrid: Trotta, 2006, p. 165-212.

[1947] 
Baigorri, A. Gabriel Tarde: el gran miedo burgués. 1994 En línea. http:// www.avizora.com/publicaciones/ciencias_sociales/textos/gran_miedo_ burgues_0014.htm. Acceso: 02/09/2011

Bajtin, M. Estética de la creación verbal. México: Siglo XXI editores, 1982, 1999.

Barthes, R. Lo obvio y lo obtuso. Barcelona: Paidós, 1986, 1995.

Battaglia, M. y Autor 2. Un acercamiento al estudio de la intertextualidad de literatura de autoayuda y corporalidad. X Congreso Argentino de Antropología Social, Universidad de Buenos Aires, 2011. http://www.xcaas.org.ar/ ponenciasDocGetfile.php? ponencialdSeleccionado=1156. Acceso: 01/02/2012 Benjamin, W. La obra de arte en la época de su reproductibilidad técnica. In: Discursos interrumpidos. Madrid: Taurus, 1973, p. 15-60. [1935]

Bloom, H. El canon occidental. Barcelona: Anagrama, 1995.

Bourdieu, P. Lo que quiere decir hablar. In Sociología y cultura. México: Grijalbo, 1990, p. 95-108.

Bourdieu, P. Razones prácticas. Barcelona: Anagrama, 1997.

Boyer, A.-M. Les paralittératures. Paris: Armand Colin, 2008.

Byrne, R. El Secreto. Barcelona: Urano, 2007.

Carozzi, M. Nueva era: la autonomía como religión. VII Jornadas sobre Alternativas Religiosas na América Latina, Sao Paulo, 1998

Chartier, R. Cultura escrita, literatura e historia. México: Fondo de Cultura Económica, 1999, 2000.

Colombres, A. Oralidad y literatura oral. Oralidad, lengua, identidad y memoria de América, 9, 1998: 15-21. ORCALC. Portal de la cultura de América Latina y el Caribe. En línea. Disponible en: http://www.lacult.org/docc/ oralidad_09_15-21-oralidad-y-literatura-oral.pdf . Acceso: 08/10/2011.

Derrida, J. Points de suspension. Entretiens. Paris: Galilée, 1992a.

Derrida, J. This Strange Institution Called Literature: an Interview with Jacques Derrida. In: Attridge, D. (edit.). Acts of literature. London /New York: Routledge, 1992b, p. 33-75.

Díaz, M. C. Los mundos del anime en Córdoba: Poéticas de los consumos culturales y sociabilidades juveniles contemporáneas. Trabajo final de licenciatura. Escuela de Historia, Universidad Nacional de Córdoba, 2011. 
Fish, S. Interpreting the "Variorum". Critical Inquiry, Vol. 2, 3 (Spring), 1976: 465-485. The University of Chicago Press.

Foucault, M. y Link, D. ¿Qué es un autor?, seguido de Apostillas a ¿Qué es un autor? Buenos Aires: El cuenco de plata, 2010.

Geertz, C. La interpretación de las culturas. Barcelona: Gedisa, 1988, 1997.

Gil, M. y Jiménez, F. El nuevo paradigma del sector del libro. Madrid: Trama, 2008.

Hall, S. Encoding/Decoding. In Hall, S. et al., Culture, Media \& Languaje. London: Hutchinson, 1980, p. 129-139.

Illouz, E. La salvación del alma moderna. Buenos Aires, Katz, 2010.

Iser, W. El proceso de lectura: enfoque fenomenológico. In: Mayoral, J.A. (comp.) Estética de la recepción. Madrid: Arco, 1987, p. 215-243.

Jakobson, R. Lingüística y Poética. Madrid: Cátedra, 1983.

Jauss, H. El lector como instancia de una nueva historia de la literatura. En Estética de la recepción. Madrid: Arco, 1987.

Jauss, H. Experiencia estética y hermenéutica literaria. Madrid: Taurus, 1992.

Kirchof, E. Literatura enquanto linguagem: o legado de Roman Jakobson. Antares, 2: 61-75, 2009.

Mur Effing, M. The Origin and Development of Self-help Literature in the United States: The Concept of Success and Happiness, an Overview. Atlantis. Journal of the Spanish Association of Anglo-American Studies. 31.2: 125-14, 2009

Niño, E. La novela rosa. El caso de los lectores de Florencia Bonelli. Trabajo final de licenciatura. Escuela de Letras, Universidad Nacional de Córdoba, 2012.

Ong, W. Oralidad y escritura. Buenos Aires: Fondo de Cultura Económica, 1987, 1993.

Autor 1. La literatura de autoayuda, una subjetividad del Sí-Mismo enajenado. La trama de la Comunicación, 11: 331-342, 2007.

Autor 1. La autoayuda: un género de la literatura masiva. XII Jornadas Nacionales de Investigadores en Comunicación, Universidad Nacional de Rosario, 2008. http://www.redcomunicacion.org/memorias. Acceso: 10/01/2012. 
Autor 1. Las lecciones de los lectores. A propósito de la recepción literaria. $V$ Coloquio de Estudios del Discurso y II Jornadas Internacionales de Discurso e Interdisciplina, Universidad Nacional de Villa María, 2011.

Autor 1. Libros de autoayuda: biblioterapia para la felicidad. Athenea digital.19: 147-169, 2010.

Petit, M. Lecturas: del espacio íntimo al espacio público. México: Fondo de Cultura Económica, 2001, 2006.

Rama, C. La economía de las industrias culturales. Buenos Aires: EUDEBA, 2003.

Ramírez, A. ¿Por qué se venden los libros que se venden? In: VV.AA., Congreso Internacional del Mundo del Libro. Memoria. México: Fondo de Cultura Económica / CONACULTA / Secretaría de Educación pública, 2009, p. 301-313.

Rosenblatt, L. La literatura como exploración. México: Fondo de Cultura Económica, 2002.

Rüdiger, F. Literatura de Autoajuda e Individualismo. Porto Alegre: Universidad de Rio Grande do Sul, 1995.

Servicio de Información Estadística Regional (SIER) / CERLALC. La edición en Iberoamérica 2008. http://www.cerlalc.org/secciones/libro_desarrollo/ El espacio iberoamericano.pdf. Acceso: 01/08/09.

Steimberg, O. Géneros. In Altamirano, C. (director), Términos críticos de sociología de la cultura. Buenos Aires: Paidós, 2002, p. 101-105.

Swingewood, A. El mito de la cultura de masas. México: Ediciones Coyoacán, 2003.

Tarde, G. La opinión y la multitud. Madrid: Taurus, 1986. [1901]

Thompson, J. B. Los media y la modernidad. Barcelona: Paidós, 1998.

Varela, M. De las culturas populares a las comunidades interpretativas. Diálogos de la comunicación, 56, 1999: 92-103.

Williams, R. Marxismo y literatura. Barcelona: Península, 1980.

Zires, M. Del rumor al tejido cultural y saber político. México: Universidad Autónoma Metropolitana - Xochimilco, 2005. 